\title{
Assessment and Containment of Aflatoxin Impact on the Health by Solar Drying
}

\author{
Smriti Gupta ${ }^{1, *}$, Shishir Kumar Verma ${ }^{1}$, Sanjay Kumar ${ }^{2}$ \\ ${ }^{1}$ Department of Zoology, Biotoxin Research Laboratory, LNMU, Darbhanga - 846008, India \\ ${ }^{2}$ Department of Physics, B.R. Ambedkar Bihar University, Muzaffarpur -842001, India \\ Corresponding E-mail: smriti79guptalgmail.com
}

\begin{abstract}
:
Solar drying is well known to human being since time immemorial. Its impact on our life is multidimensional. However, gradual changes in our life style have consistently reduced its positive impact during last century. It is more evident in towns. One of them is contamination of dietary items by fungi, which produces carcinogens. The ubiquitous fungus Aspergillus flavus is notorious for contaminating many important crops and food stuffs with the carcinogenic mytoxin, aflatoxin. The Aspergillus spp., are widely spread in nature and contaminated food supplies of humans and animals resulting in health hazards and even death. A detail survey of wholesale depots was made to assess the impact of aflatoxin on the health of the human and other animals by the natural contamination of the dietary items. Samples of different dietary items collected from different wholesale depots belonging to five different mohallas of Darbhanga town (Bihar, India) during 2012 were brought to the laboratory for further studies. The findings suggest that Aspergillus flavus appeared as the most dominant mycoflora in general. Present bioassay on Daphnia magna subjected to static exposure of different concentration of A. flavus crude extract clearly indicate the stain to be potential toxic producer. The rate of mortality increased with increased in amount of toxin. Solar drying is a cost-effective solution to overcome this serious problem. The technology is well developed and tested. In this paper, appropriate solar dryer design is further proposed for households to eliminate this serious health hazard.
\end{abstract}

Keywords: Solar Drying, Aspergillus Flavus, Aflatoxin, Carcinogenic Mycotoxin, Health Hazards

\section{Introduction}

Solar drying is well known to human being since time immemorial. Its impact on our life is multidimensional. Solar drying has been considered as one of the most promising area for the utilization of solar energy, especially in the field of food preservation. Open sun drying is the most common method employed in tropical countries for the drying of agricultural products, food stuffs. However, gradual changes in our lifestyle have consistently reduced its positive impact during last century. It is more evident in towns. One of them is contamination of dietary items by fungi, which produces carcinogens. The ubiquitous fungus Aspergillus flavus is notorious for contaminating many important crops and food stuffs with the carcinogenic mycotoxin, aflatoxin [1]. The Aspergillus species are widely spread in nature and contaminated food supplies of humans and animals resulting health hazards and even death $[2,3]$.

Most of the agricultural commodities and their byproducts are susceptible to fungal spoilage in pre- and post-harvest condition. However, from mold spoilage point of view storage period has been recorded as most critical. The climatic factors in the present area of investigation is characterized by extreme of hot and cold added with high range of relative humidity. These factors make the agricultural commodities most-vulnerable to mycobial spoilage. The climatic factors like atmospheric temperature and $\mathrm{RH}$ are beyond control and infestation of the substrates also cannot be fully checked. But water content of the substrate before storage can be brought down to quite a "Low-risk-rang" by adopting simple "Sun drying" in a proper way. Solar drying has been considered as one of the most-promising areas for the utilization of solar energy, especially in the field of food preservation. Open sun drying is the most common method employed in tropical countries for the drying of agricultural products, food stuffs etc.

A detail survey of wholesale depots was made to assess the impact of Aflatoxin on the health of the human and other animals by the natural contamination of the dietary items. Samples of different dietary items collected from different wholesale depots belonging to five different mohallas of Darbhanga town (Bihar India) during 2012 brought to the laboratory for further studies. In this paper, 
appropriate solar dryer design is further proposed for households to eliminate this serious health hazard.

\section{Materials and Methods}

\subsection{Area of Survey and Sampling}

Five Mohallas of Laheriasarai (Darbhanga district) like Benta, Gudri bazaar, Imambari, Bangalitola and Balbhadrapur were selected to carry out present survey. The target sites were Whole sale depots. The samples werecollected once in a year i.e during September 2012 representing Monsoon. Random samples (50-100gm each) of Rice (R), Wheat (W), Maize (MZ), Gram (GR), Pea (P), Moong (MG), Arhar (A), Urad (U), Mustard (M), Coriander (C), Flatrice (FR), Mashur (MSH), Potato (PT), Chilli (CH), Garlic (G). Samples taken in sterilized polythene bags and brought to the laboratory were examined physically for apparent fungal growth minutely. Subsamples (10 g each) were subjected to routine culture by, Blotter technique and Solid medium technique (Agar plate technique).

Asthana Howker's 'A' (AH) and Czapak's Agar (CZ) medium was used simultaneously in each case. The medium was poured in Petri plates and autoclaved for 15 minutes at $15 \mathrm{lb}$. pressure. The thoroughly mixed sample were spread over the medium in random spots and incubated for 7-10 days in B.O.D at $28 \pm 2^{0} \mathrm{C}$.

\subsection{Identification}

The fungal colonies appearing on the substrate were identified morphologically on the basis of colour appearance. Individual fungal isolates were identified at generic level and in some cases at species level on the basis of micromorphological features following Moreau [4] and Wyllie and Morehouse [5].

\subsection{Pure culture}

Identified toxigenic strain of A. flavus was mass cultured on coarsely ground wheat as suggested by Schindler and Nesheim [6]. The substrate, before inoculation, was sterilized at $15 \mathrm{lb}$. pressure for 15 minutes. The inoculated substrate was incubated in B.O.D at $26 \mathrm{I} 2^{\circ} \mathrm{C}$ for 12 days.

\subsection{Bioassay}

The bioassay was conducted on Daphnia magna, Sensitive model for bioassay tests.

\section{Observation}

All together 1121 samples were collected of which 299 were infected and partially infected and 822 appeared as fresh (Table-1) along with the physical condition. Percentage of contamination varied between 7 to 31 being lowest in case of Garlic and maximum in the case of Pea. However, in general more than $20 \%$ of all the sample, irrespective of their type, were contaminated.

The samples identified fresh in physical examination were subjected to culture by the same methods. This revealed that about 26.62 percent of the fresh samples were also

Table 1: Microbial infestation on Samples collected from Whole sale depots once in a year

\begin{tabular}{|l|l|l|l|l|l|l|}
\hline \multicolumn{7}{|c|}{ Store houses (Annual) } \\
\hline SI. No. & Items & Total Number & Infected & $\%$ & Fresh & $\%$ \\
\hline 1. & Rice & 75 & 22 & 29.33 & 53 & 90.66 \\
\hline 2. & Wheat & 75 & 25 & 33.33 & 50 & 66.66 \\
\hline 3. & Maize & 75 & 18 & 24.00 & 57 & 76 \\
\hline 4. & Gram & 74 & 22 & 29.72 & 52 & 70.27 \\
\hline 5. & Pea & 75 & 31 & 41.33 & 44 & 58.66 \\
\hline 6. & Mung & 75 & 24 & 32.00 & 51 & 68.00 \\
\hline 7. & Arhar & 75 & 23 & 30.66 & 52 & 69.33 \\
\hline 8. & Urad & 75 & 23 & 30.66 & 52 & 69.33 \\
\hline 9. & Mustard & 75 & 28 & 37.33 & 47 & 62.66 \\
\hline 10. & Coriander & 74 & 16 & 21.62 & 58 & 78.37 \\
\hline 11. & Flat rice & 75 & 22 & 29.33 & 53 & 70.66 \\
\hline 12. & Mashur & 75 & 20 & 26.66 & 55 & 73.33 \\
\hline 13. & Potato & 75 & 9 & 12.00 & 66 & 88.00 \\
\hline 14. & Chilli & 75 & 9 & 12.00 & 66 & 88.00 \\
\hline 15. & Garlic & 73 & 7 & 9.58 & 66 & 90.41 \\
\hline
\end{tabular}


Table 2: Fungal infestation appearing on various substrates following incubation

\begin{tabular}{|l|l|l|l|l|l|l|l|}
\hline \multirow{2}{*}{ Substrate } & \multicolumn{3}{|c|}{ Winter } & \multicolumn{3}{c|}{ Summer } & \multicolumn{2}{c|}{ Monsoon } \\
\cline { 2 - 7 } & $\begin{array}{l}\text { No. of Fresh } \\
\text { samples }\end{array}$ & $\begin{array}{l}\text { Infesting after } \\
\text { incubation (\%) }\end{array}$ & $\begin{array}{l}\text { No. of Fresh } \\
\text { samples }\end{array}$ & $\begin{array}{l}\text { Infesting after } \\
\text { incubation (\%) }\end{array}$ & $\begin{array}{l}\text { No. of Fresh } \\
\text { samples }\end{array}$ & $\begin{array}{l}\text { Infesting after } \\
\text { incubation (\%) }\end{array}$ & \\
\hline Flat Rice & 47 & 19.14 & 48 & 18.75 & 48 & 14.58 & 17.49 \\
\hline Potato & 64 & 20.31 & 60 & 15.00 & 67 & 17.91 & 17.74 \\
\hline Mustard & 49 & 18.36 & 51 & 15.68 & 53 & 15.09 & 16.37 \\
\hline Garlic & 67 & 14.92 & 67 & 16.41 & 66 & 16.66 & 15.99 \\
\hline Rice & 39 & 17.94 & 34 & 11.76 & 32 & 18.75 & 16.15 \\
\hline Wheat & 34 & 11.76 & 36 & 19.44 & 35 & 11.42 & 14.20 \\
\hline Maize & 35 & 11.42 & 37 & 16.21 & 39 & 12.82 & 13.48 \\
\hline Arhar & 33 & 18.18 & 29 & 17.24 & 33 & 15.15 & 16.85 \\
\hline Urad & 14 & 14.28 & 21 & 19.0 & 19 & 15.7 & 16.32 \\
\hline Coriander & 19 & 21.00 & 20 & 20.00 & 19 & 15.7 & 18.90 \\
\hline Mashur & 21 & 14.28 & 18 & 11.11 & 16 & 12.5 & 12.63 \\
\hline Chilli & 21 & 19.04 & 23 & 13.04 & 22 & 18.18 & 16.75 \\
\hline Gram & 34 & 17.64 & 39 & 17.94 & 37 & 10.8 & 15.76 \\
\hline Pea & 16 & 18.75 & 13 & 15.38 & 15 & 13.3 & 15.81 \\
\hline Mung & 15 & 11.76 & 14 & 14.28 & 19 & 15.7 & 13.91 \\
\hline
\end{tabular}

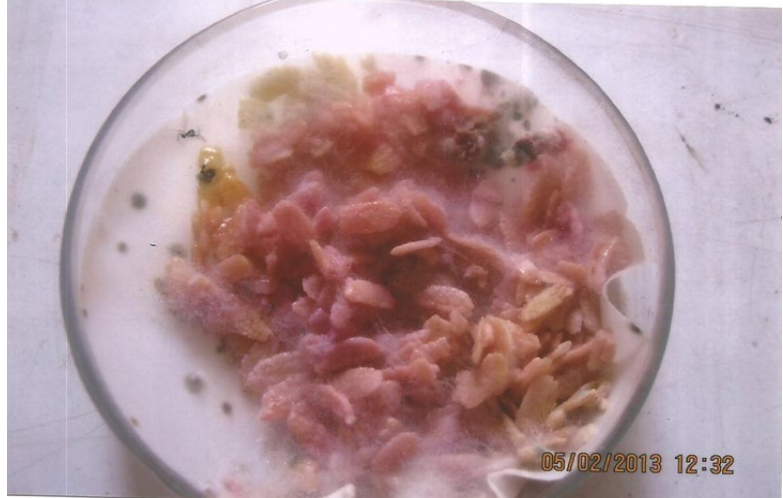

Figure 1: Appearance of Aspergillus group and other Mycoflora on Flat Rice collected during winter

infected with various strains of toxic fungi (Table-2). Identification of these fungi revealed that Aspergillus groups dominated all the substrate except Rice, Mustard, Flat rice. The finding suggested that Aspergillus flavus appeared as the most dominant mycoflora in general.

Aspergillus flavus is the most toxic strains identified during present investigation. This species was sub cultured and toxin extract was prepared for bioassay. The result has been presented ahead. The bioassay was conducted on Daphnia magna, a sensitive model for bioassay tests. The findings suggest that different dose level $(0.5,1.0,1.5,2.0$ and $2.5 \mathrm{ml})$ of the crude toxin extract ( $1 \mathrm{mg}$ crude aflatoxins dissolved in $100 \mathrm{ml}$. Of sterilized distilled water) was toxic to the test animals. At $0.5 \mathrm{ml}$ of

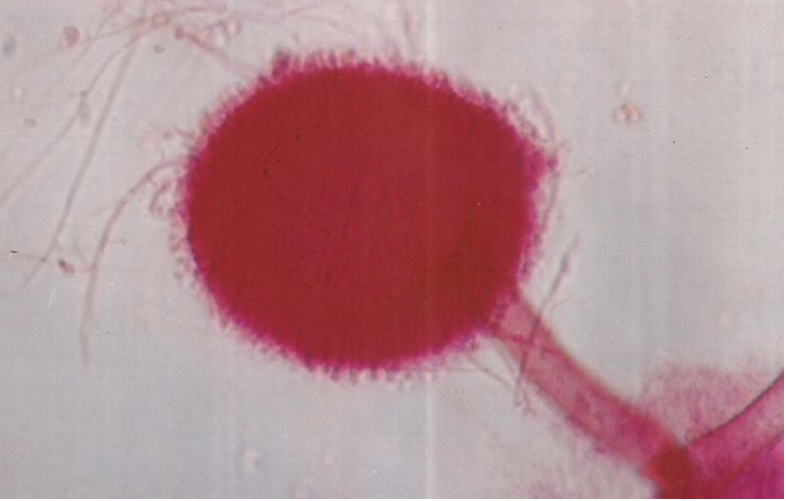

Figure 2: Conidial head of $A$. flavus strain x600

the toxin $44 \%$ of the population died after $16 \mathrm{hrs}$. of exposure while at $2.5 \mathrm{ml}$ dose level $91 \%$ of the test animals died.

Preventive measures: - Solar drying is one of the most prevailing methods of food preservation, where the moisture is removed preventing the growth of microorganisms that causes food damage. This method helps in reducing the weight and volume of the product which reduces the transportation and storage load and also helps in the storing the food in ambient temperature. Solar cabinet drier widely used for drying of farm products such as spices and fruits $[7,8]$. It has a collector at the top and a drying chamber at the bottom this arrangement limits direct exposure of the sunlight on the product, which helps 
Assessment and Containment of Aflatoxin Impact on the Health by Solar Drying

Table 3: Effect of crude aflatoxin B1 extract on Daphnia magna on the basis of \%age of death at different dose/time intervals

\begin{tabular}{|c|c|c|c|c|c|c|c|c|c|c|}
\hline \multirow{3}{*}{$\begin{array}{l}\text { Amount of } \\
\text { crude toxin } \\
\text { (in ml.) }\end{array}$} & \multicolumn{10}{|c|}{ Number of neonates died out of 20 in different time periods } \\
\hline & \multicolumn{2}{|c|}{1 hr. } & \multicolumn{2}{|c|}{2 hrs. } & \multicolumn{2}{|c|}{4 hrs. } & \multicolumn{2}{|c|}{8 hrs. } & \multicolumn{2}{|c|}{16 hrs. } \\
\hline & $\begin{array}{l}\text { Death in } \\
\text { No. }\end{array}$ & $\begin{array}{l}\text { Death } \\
\text { in \% }\end{array}$ & $\begin{array}{l}\text { Death in } \\
\text { No. }\end{array}$ & $\begin{array}{l}\text { Death } \\
\text { in } \%\end{array}$ & $\begin{array}{l}\text { Death in } \\
\text { No. }\end{array}$ & $\begin{array}{l}\text { Death } \\
\text { in \% }\end{array}$ & $\begin{array}{l}\text { Death in } \\
\text { No. }\end{array}$ & $\begin{array}{l}\text { Death } \\
\text { in \% }\end{array}$ & $\begin{array}{l}\text { Death in } \\
\text { No. }\end{array}$ & $\begin{array}{l}\text { Death } \\
\text { in \% }\end{array}$ \\
\hline 0.5 & $1.8 \pm 0.51$ & 9 & $3.5 \pm 1.1$ & 17.5 & $6.8 \pm 0.73$ & 34 & $8.2 \pm 0.39$ & 41 & $8.8 \pm 0.73$ & 44 \\
\hline 1.0 & $2.6 \pm 0.49$ & 13 & $4.2 \pm 0.74$ & 21 & $10 \pm 0.54$ & 50 & $10.14 \pm 1.13$ & 50.7 & $12.6 \pm 0.96$ & 63 \\
\hline 1.5 & $3.8 \pm 0.73$ & 19 & $5.4 \pm 0.78$ & 27 & $7.2 \pm 0.73$ & 36 & $12.8 \pm 1.1$ & 64 & $14.8 \pm 0.96$ & 74 \\
\hline 2.0 & $5.2 \pm 0.74$ & 26 & $7.2 \pm 0.74$ & 36 & $13.2 \pm 0.74$ & 66 & $15.6 \pm 0.48$ & 78 & $17.4 \pm 0.8$ & 87 \\
\hline 2.5 & $6.8 \pm 1.16$ & 34 & $10 \pm 0.63$ & 50 & $16 \pm 0.63$ & 80 & $17.8 \pm 0.4$ & 89 & $18.2 \pm 0.4$ & 91 \\
\hline
\end{tabular}

in retaining the natural colour and good nutritional value. The loading capacity is $4 \mathrm{~kg}$. per batch and has axial fans of $20 \mathrm{Watt}$, provided for air circulation.

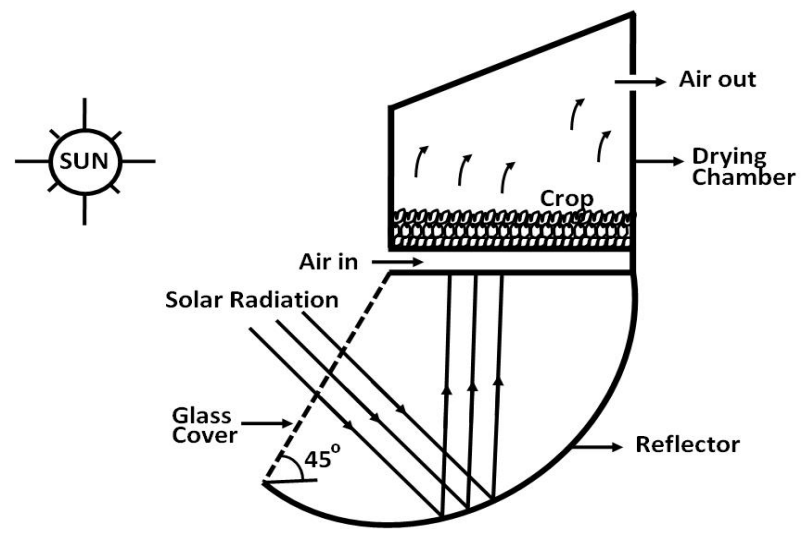

Figure 3: Block diagram of solar cabinet drier

The combined action of solar radiation incident directly on the product to be dried and hot air provides the necessary heat required for the drying process. In most cases, the air is warmed during its flow through a low pressure drop solar collector and passes through air ducts into the drying chamber and over drying trays containing the crops. The moist air is then discharged through air vents or a chimney at the top of the chamber heated air flows through the stack of trays until the entire products is dry. As the hot air enters through the bottom tray, this tray will dry first. The last tray to dry is the one at the top of the chamber.

\section{Results and Discussion}

Most of the agriculture commodities and their products are susceptible to fungal spoilage in different pre-and post-harvest condition. However, from mold contamination point of view storage period has been regarded as the most critical [3]. Aspergillus have been recognized as storage fungi taking over and dominating over the substrates. Thus, the present work emphasizes survey of the human dietary items stored at wholesale depots. It was observed that in wholesale depots the walls and ceilings of wholesale depots were frequently observed moist. The dietary commodities were found to be lying on uncommented ground in direct contact of soil in gunny bags or in contact with the earthen walls. Such condition provide opportunity for the moisture to penetrate the substrates, which consequently result in high fungal contamination.

The growth of fungi and mycotoxin synthesis is conditioned by variety of ecological parameters. Water activity is the most important factor influencing on speculation and growth of fungi and Subsequent mycotoxin production added with atmospheric temperature. The acidity $(\mathrm{pH})$ of nutrient medium and substrate essentially influence the growth of fungi and subsequent mycotoxin production added with atmospheric temperature. Solar drying can be most successfully employed as cost effective drying technique $[7,8]$. It has got several attractive features. For example, energy is available free of cost and can be harnessed in the site itself controlling drying is also possible by this method, and it enhances the quality of dried products.

\section{Conclusion}

The growth of fungi and mycotoxin synthesis is conditioned by variety of ecological parameters. Water activity is the most important factor influencing on speculation and growth of fungi and Subsequent mycotoxin production added with atmospheric temperature. The acidity $(\mathrm{pH})$ of nutrient medium and substrate essentially influence the growth of fungi and subsequent mycotoxin production added with atmospheric temperature. Solar drying is a promising technology for drying of food products. This can dramatically reduce the post-harvest spoilage and also 
prevent the human being from different types of diseases caused by mycotoxins.

\section{References}

[1] Troller JA and Christian JHB (2012), Water Activity and Food, Elsevier, USA.

[2] Kerstin Hell, Charity Mutegi (2011), Aflatoxin control and prevention strategies in key crops of Sub-Saharan Africa, African journal of microbiology Research, 5(5), 459-466.

[3] Reddy KRN, Farhana Nl, Salleh B (2011), Occurrence of Aspergillus spp. and aflatoxin B1 in Malaysian foods used for human consumption, Journal of Food Science, 76, 99 104.

[4] Moreau, C. (1974), Moulds, Toxins and Food, John Wiley \& Sons, NewYork, USA.

[5] Wyllie TD and Morehouse LG, Mycotoxic Fungi, Mycotoxins, Mycotoxicoses - An Encyclopedic Handbook, Marcel Dekker Inc., USA

[6] Schindler AF and Nesheim S (1970), Effect of moisture and incubation time on ochratoxin: a production by an isolate of Aspergillus Ochraceous, J. Assoc. Anal. Chem., $53,89-91$.

[7] Sreekumar A, Mani Kantan PE (2008), Performance of Indirect Solar Cabinet Drier, Energy convers. \&mgmt, 1388-1395.

[8] Bal LM, Satya S, Naik SN (2010), Solar dryer with thermal energy storage systems for drying agricultural food products: a review, Renewable and Sustainable Energy Reviews, 14 (8):2298-2314 